
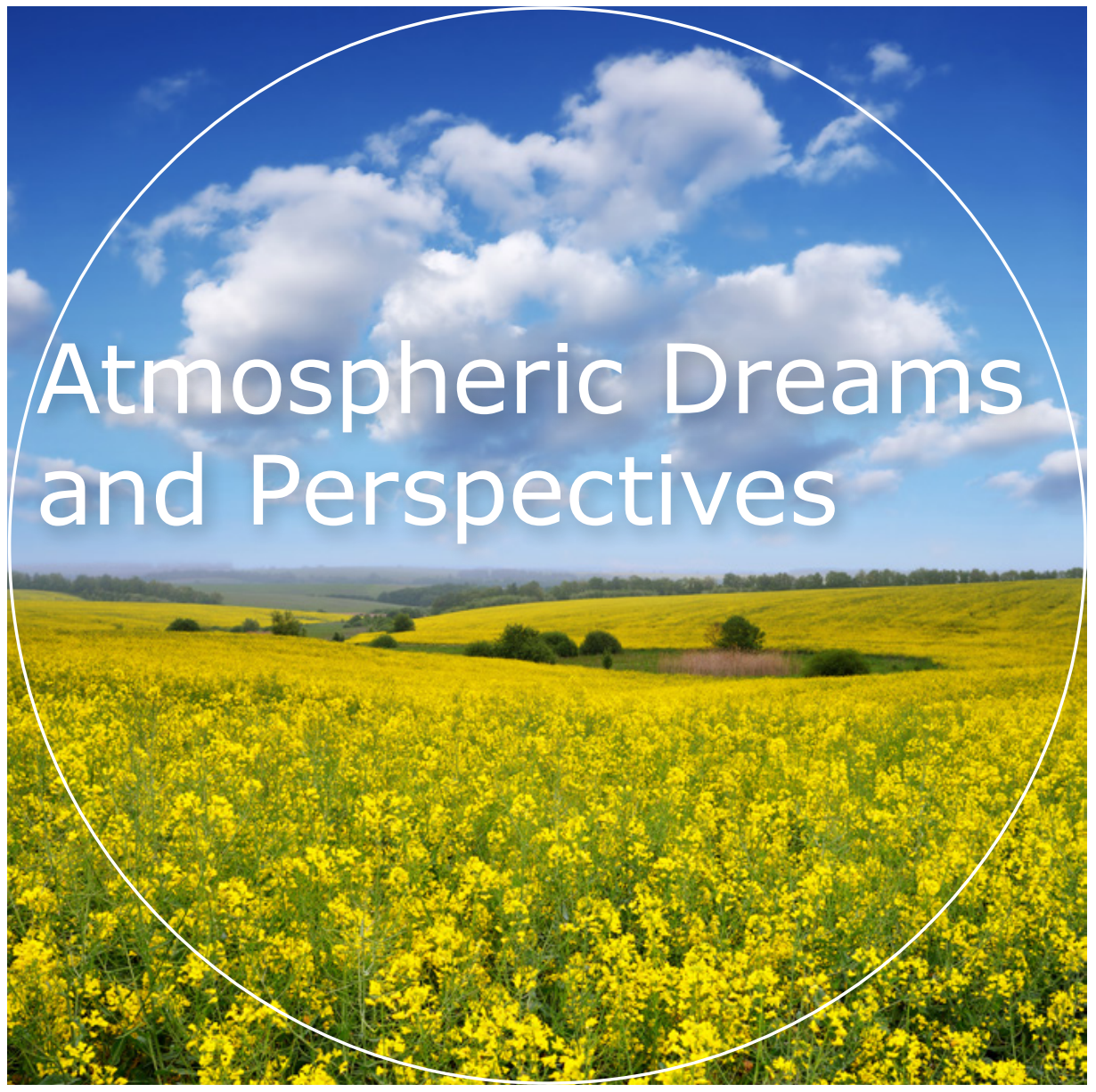

Prof.dr Bert Holtslag

Farewell address upon retiring as Professor of Meteorology at Wageningen University \& Research on 10 October 2019 



\section{Atmospheric Dreams and Perspectives}

\section{Prof.dr Bert Holtslag}

Farewell address upon retiring as Professor of Meteorology at Wageningen University \& Research on 10 October 2019 
DOI https://doi.org/10.18174/508092

ISBN 978-94-6395-232-3

(C)2019 Prof.dr Bert Holtslag. All rights reserved. No parts of this publication may be reproduced by print, photocopy, stored in a retrieval system or transmitted by any means without the prior written permission of the author. 


\section{Atmospheric Dreams and Perspectives}

\section{Esteemed Rector Magnificus, Dear Colleagues, Students, Family and Friends,}

It is a great pleasure to see so many of you today at my farewell address as professor and chair of Meteorology at Wageningen University. I have held this position for more than 20 years doing research in cooperation with many colleagues, guiding students and lecturing. Today I would like to share with you some of the scientific dreams within the atmospheric sciences and the perspectives of making these dreams come true. You may note that an "Atmospheric Perspective" can also refer to the perspective in a landscape picture benefiting of the breaking of light in the atmosphere.

In this farewell address, I would like to talk about the silent revolution in Meteorology, proceed then with advancing the understanding of atmospheric processes for weather and climate, and finally talk about the impacts of land use and urbanisation on the atmosphere. The picture on the cover also shows my favourite type of fair weather, not just clear skies but with some fair weather clouds in this case over a heterogeneous landscape. 


\section{Silent Revolution in Meteorology}

Let us first go back in time some 2300 years. Around the year $340 \mathrm{BC}$, the philosopher Aristoteles wrote his masterpiece "Meteorologica". In fact, it is a book in four volumes. The text discusses already many of the aspects common to air and water, as well as their interactions with the earth's surface [7]. Nowadays we would refer to this as the components of the hydrological cycle. I was actually surprised to see how many relevant subjects he already covered so long ago, and many of these subjects are in our study books of Meteorology even today [28].

Connecting to this, one of the long standing dreams by mankind, is to understand and predict the weather. One can imagine, that also in the old days people like to talk about the weather and how it might change. As such there is a significant body of informal folklore related to the prediction of the weather, which we know as the weather lore's. Some of these are based on real physics, but others are really folklore in contrast to what some people believe [29].

Figure 1 shows a comparison of an atmospheric weather forecast model with independent cloud observations by a satellite. This is an example from some time ago using the weather forecast model of the European Centre for Medium Range Weather Forecasts (ECMWF) in comparison with the Meteorological Satellite (MeteoSat) observations. In fact, it is difficult to tell beforehand, which one is the model result and which one is by the observations. Overall the large-scale behaviour of the atmosphere as seen by the cloud motions, is well reproduced by the weather forecast model. So this part of the dream has certainly become true!
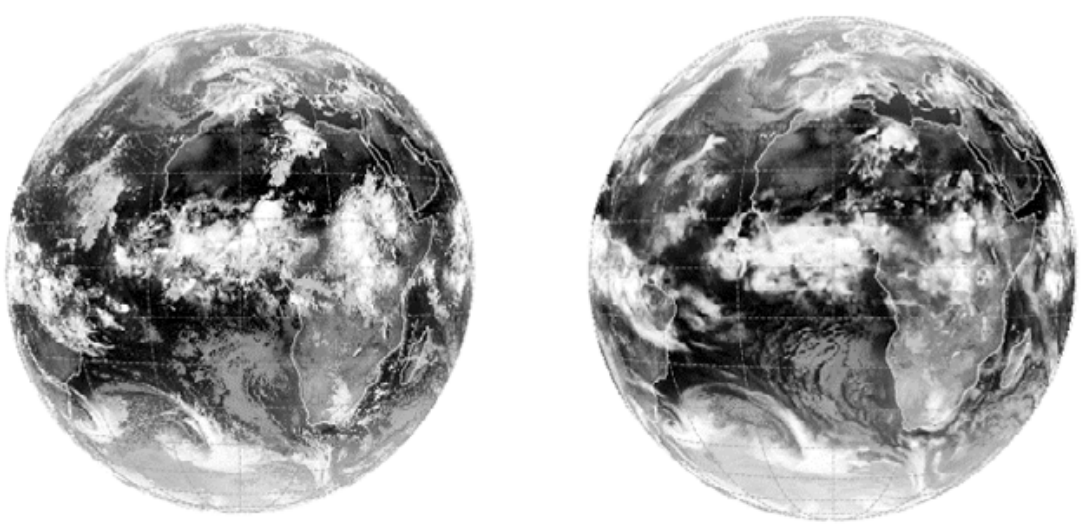

Figure 1 - A comparison of MeteoSat cloud observations (left hand side) versus weather forecasts by ECMWF (right hand side) 
Much of the progress in Meteorology, has been achieved over the last 40 years. The improvement in forecast skill is now referred to as the silent revolution in

Meteorology, a term introduced by Peter Bauer and colleagues at ECMWF in 2015 [1]. In fact, a forecast of the large-scale weather pattern for a week ahead is nowadays roughly as good as a 3 -day forecast 40 years ago. The achievement was made possible due to the enormous increase of computing power, observations by satellites and other instruments, but also by enhanced insights in the behaviour and the physics of the atmosphere ("what we refer to as the Meteorology").

Many of you do take notice of all the weather information which is available through apps, news media and websites. And this is still progressing. At the Meteorology and Air Quality group, a prototype for an App for a mobile phone was made providing forecasts of human comfort [10]. Mobile phones are also found useful to extract local weather observations like for temperature and precipitation, which is an active field of research at this university too by the Hydrology and Meteorology groups [27]. And of course we should mention the popularity of the weather radar. Just by extrapolation of observed rain by the radar, useful outlooks are made, but only for a few hours ahead at most. Note that the extrapolation of the same initial data can be done differently by the various providers, which also explains why the radar patterns can be different.

Over the years the performance of weather forecasts has increased, but why is it never perfect? Due to the work of Ed Lorenz [19] and others, we now know that the atmosphere behaves like a complex system, which can be quite sensitive to initial conditions. This is known as the butterfly effect, which can be formulated by this question: Does the flap of a butterfly's wings in Brazil, set off a tornado in Texas? Or even in the Netherlands? To explore the sensitivity of the atmosphere at a certain moment, many alternate forecasts for a specific situation are made by varying the initial conditions of the weather forecast model. This is known as the Ensemble Prediction System (EPS).

Examples for the evolution of the actual weather of this can be found on websites of various weather institutes and agencies, like Figure 2 adapted from the website of KNMI using results of ECMWF [18]. In addition to a reference forecast with a horizontal grid spacing of roughly $10 \mathrm{~km}, 5^{1}$ alternate weather forecasts are provided by the ECMWF model with a factor two lower resolution. When the forecasts are similar, the atmosphere is apparently not that sensitive to initial disturbances and then the forecast is quite certain for that situation and region. Vice versa, when the forecasts are very different, the atmosphere is apparently quite sensitive to initial disturbances and then the forecast is uncertain. This happens to be the case for the 
example of Figure 2 showing the EPS for precipitation. The forecast was made one week ago, and it confirms that for today (Thursday Oct. 10) the forecast was uncertain, but that precipitation is likely (as we have experienced today).

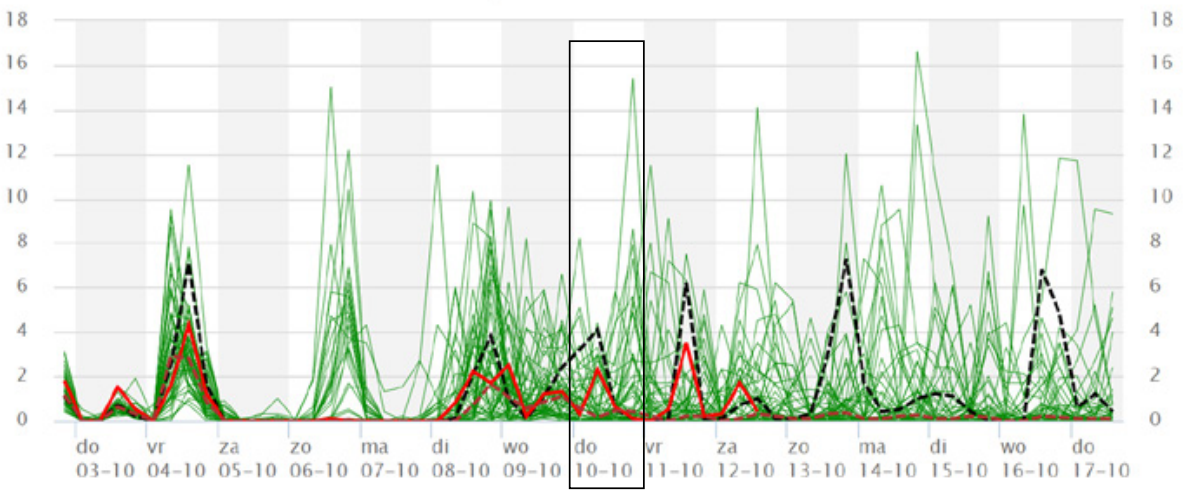

Figure 2 - Precipitation forecasts by Ensemble Prediction System (EPS) starting with the analysis for October 2, 2019. In the square the model results for October 10 are given [18]

It is not difficult to envision, that in the future weather forecast models will provide even more detailed information with higher resolution and more ensemble members. Such forecasts will be adapted for various applications like for instance solar and wind energy resources. The perspectives for doing this are really excellent! In passing by, we may note that the size of the atmospheric butterfly is not that small in these model results, because of the model grid spacing of $20 \mathrm{~km}$ in the ensemble runs. An important application of the EPS is for severe weather warnings, such as early warnings for storms or severe heat waves. Society needs to be informed well in time, and in times of climate warming and variable weather, this is very important. Also the vulnerability of society has increased, making timely weather forecasts even more important.

The quality of the weather forecast depends strongly on the size and duration of the weather events. Figure 3 shows various weather phenomena in relation to their size and duration. For severe storms, tropical cyclones and larger scale weather phenomena, the forecast quality has increased as mentioned before and the use of the EPS is very helpful. But for a smaller scale weather event like a tornado it is very difficult to predict where and when it will occur before it is actually formed. 
Let me make a personal note shortly. I grew up in the small city of Borculo in the Eastern part of the Netherlands. That city is still known for the severe weather which occurred in the early evening of August 10, 1925. Locally this is known as the 'cyclone' of Borculo, which is actually not a good name since a cyclone is active on much larger scales (see Figure 3). In fact from the damage on the buildings it would have been a tornado or a strong down burst connected to the severe weather [4]. In retrospect, I think my interest in weather and climate started as a school boy, because in Borculo so much still remembers to this weather event, like the 'cyclone' park and houses which are named after the cities who donated them for the rebuilding of the city.

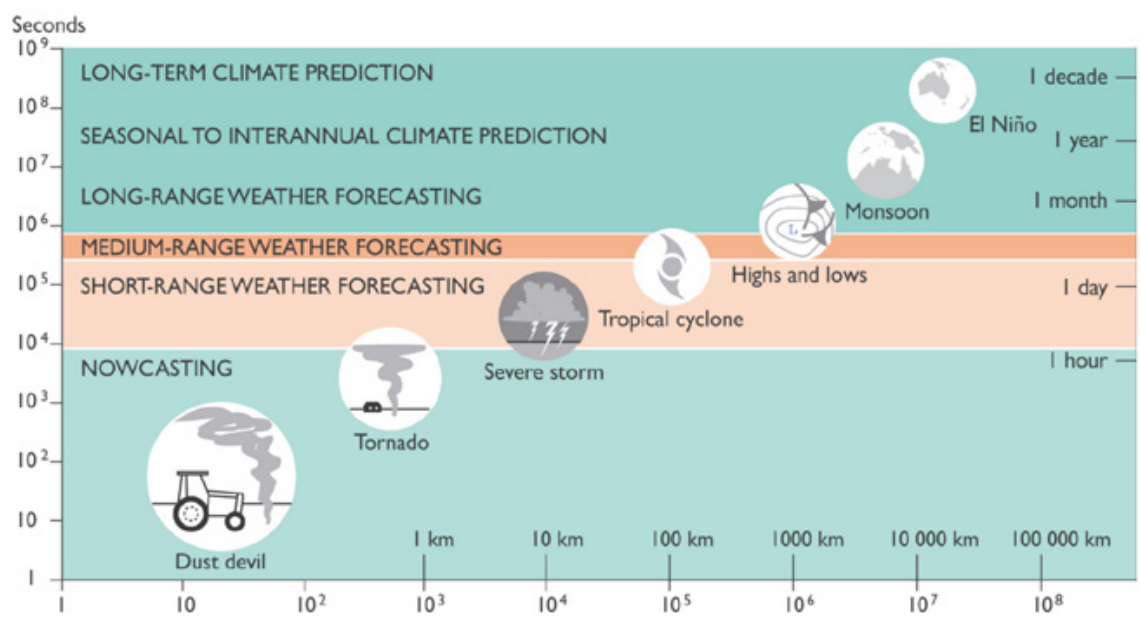

Figure 3-Atmospheric phenomena with characteristic sizes and durations [30]

I like to proceed with a phenomenon of which the signal is prominent on the global scale, namely climate warming. The observed increase in near surface temperatures since 1850 over land is around $1.5^{\circ} \mathrm{C}$ already and is now around $I^{\circ} \mathrm{C}$ globally averaged [14]. To keep climate warming well within the $2{ }^{\circ} \mathrm{C}$ limit of the Paris agreement, it was (again) concluded that this can only be achieved by "reducing greenhouse gas emissions from all sectors, including land and food". This will be a major challenge and would need collective action by all of us, the sooner the better.

To inform people who are not directly in this field of science, it is very important to make appealing illustrations and animations. Recently a so-called climate spiral animation was created by Ed Hawkins and colleagues at Reading University [8]. 
It shows how global temperature has been increasing over time for each month since 1850 like illustrated in Figure 4 for the months in 2018. Apparently the animation was very appealing since it was shown and shared on social media millions of times. In fact, in some of the months the global averaged temperature already has increased by almost $1.5^{\circ} \mathrm{C}$. Similar spirals have been made for the increase of carbon dioxide and other climate variables.

Hopefully the information as given by climate spirals, creates a

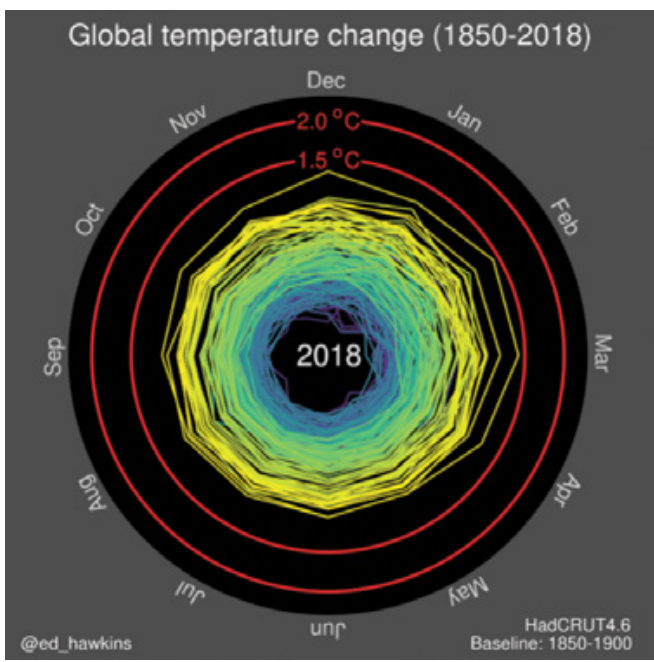

Figure 4 - The climate Spiral: Global temperature change indicated for each month in 2018 [8] wider climate awareness and support for a much needed climate policy. From a scientific point of view, it is clear that mankind has modified the composition of the atmosphere which does impact weather and climate. The question is to what extent so-called 'solar radiation management' may help us by artificial enhancing the albedo of the atmosphere. However, with such an approach no real control of weather and climate can be achieved. Many other actions can be taken and are already taken, which are also beneficial for many other purposes in life and society (see Figure 5). Some people may say, are you dreaming? But we do not have much of a choice. For the Netherlands it can be even essential to limit global warming, because of the anticipated sea level rise which may occur within the coming centuries if policies are not

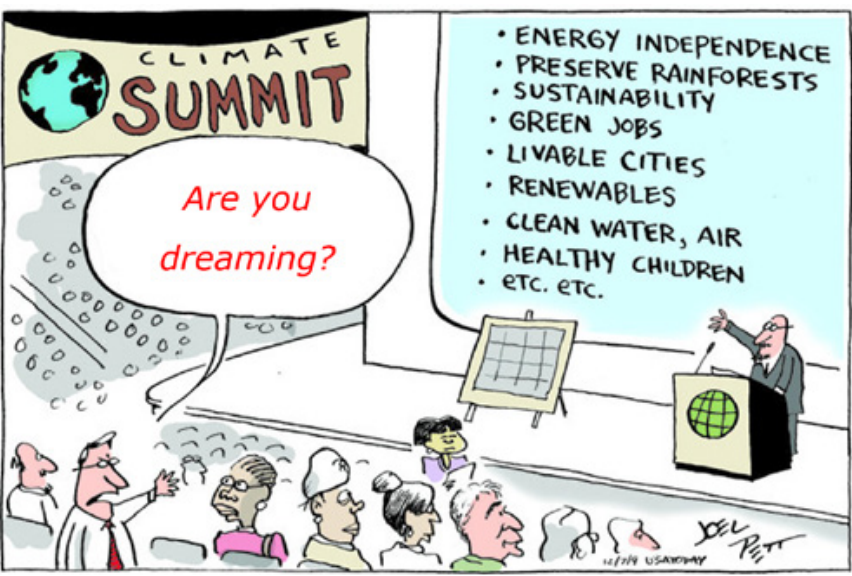
changed.

Figure 5 - Climate summit cartoon (modified after the original by Joel Pett) 


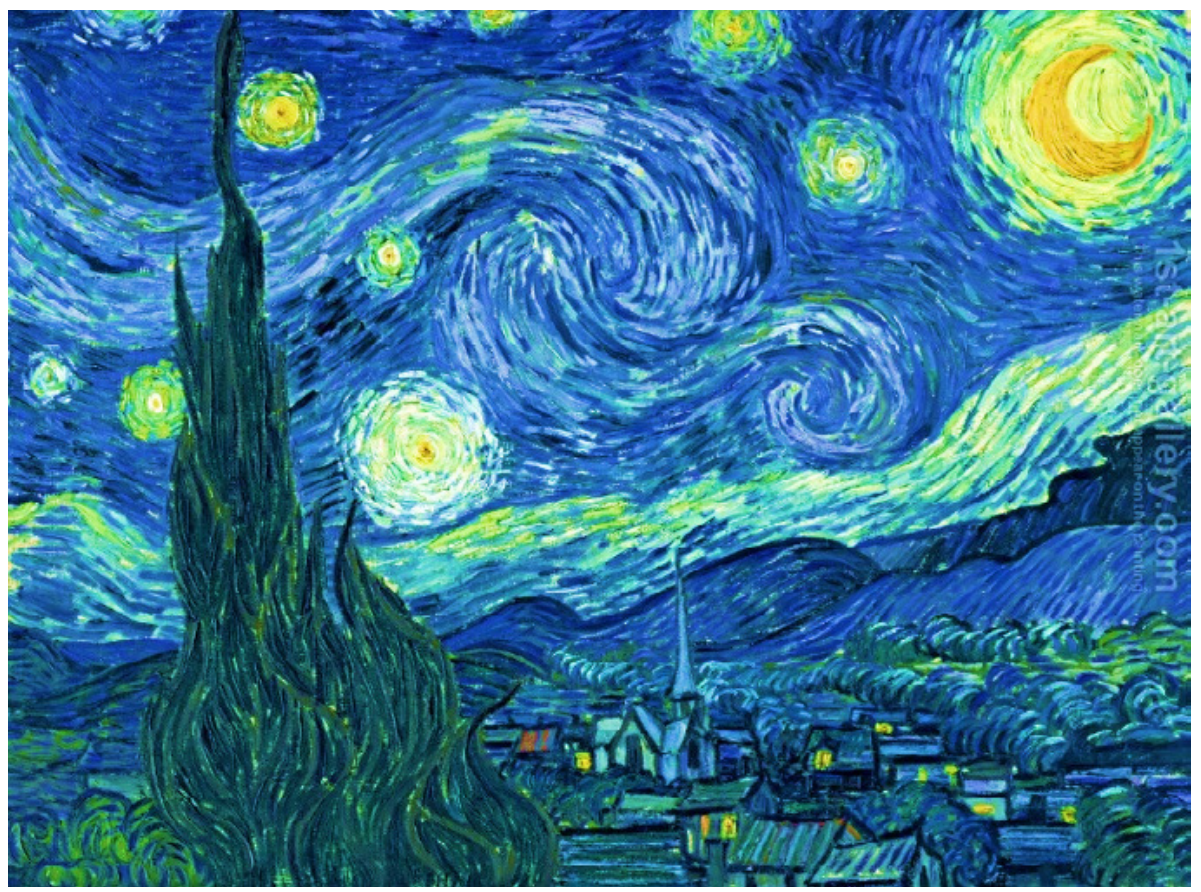

Figure 6 - Starry Night by Vincent van Gogh, 1889

\section{Advancing the Understanding of Atmospheric Processes}

I would like to proceed with the understanding of atmospheric processes which are playing an essential role for weather and climate. In his painting "Starry Night", Vincent van Gogh came up with a nice visualization of the atmosphere over land (Figure 6). The twinkling of the stars are caused here by the scintillation of light by the stars. And this scintillation is the result of atmospheric turbulence far above the surface.

The obvious atmospheric dream is to fully understand all relevant atmospheric processes and to represent these with sufficient detail in models for weather forecasting and climate research. However, there are still many challenges such as the formation and evolution of clouds, the changing composition of the atmosphere, the interaction of the atmosphere with the earth's surface, among other processes. Note that the presence of hills and mountains can create so-called gravity waves, which can break-up and cause atmospheric turbulence well above the surface. Within turbulence irregular motions exist, which impact the breaking and scintillation of light as was pictured in Starry Night. 
The small-scale atmospheric processes need to be represented in the atmospheric models with sufficient detail. There has been substantial progress on this over the years, but there is still considerable uncertainty on how to best represent these processes. This is tedious work and often this is taken for granted by model users. In fact, the work on improved modelling of atmospheric processes would deserve much more recognition of the scientific community [15].

Over the years, the Meteorology and Air Quality (MAQ) section at Wageningen University has given much attention to the land surface and how it interacts with the atmosphere. Heating of the land by the sun during daytime results in the exchange of heat and moisture between the land surface and the atmosphere. Nowadays these processes can be well measured, for instance by using the scintillations of atmospheric turbulence in the lower atmosphere. The MAQ group has made great contributions over the years by developing novel instruments for observing the heat exchanges using scintillations on horizontal distances from a few $100 \mathrm{~m}$ 's to even 10 $\mathrm{km}$. The instruments are now also commercially available thanks to the efforts of Henk de Bruin, Oscar Hartogensis, and involved PhD students [16].

Because of the enormous increase of computing facilities, the exchange processes of heat and moisture can nowadays also be simulated with very great detail [23]. For instance, formation of fair weather shallow cumulus clouds over a land surface in response to the heat exchanges at the land surface can be studied on a scale of $10 \mathrm{~km}$ or so with a horizontal resolution of only $50 \mathrm{~m}$ and about $10 \mathrm{~m}$ in the vertical. As such the exchange processes between the land and the atmosphere can be calculated in great detail and compared by independent observations. The enhanced possibilities for observations and model simulations, have created great opportunities to advance this research theme. However, it is complex because of the many processes and atmospheric scales involved, and because of the land-surface heterogeneity [6]. Even for clear skies, it appears that atmospheric models still may suffer from errors.

Figure 7 shows the results of state of the art models in use for weather forecasting and climate research, in comparison with observations at the Dutch observational facility in Cabauw (near the $200 \mathrm{~m}$ meteorological tower operated by KNMI). In particular at night a large range of model results is seen, which can strongly deviate from the observations. Much of this discrepancy seems related to the coupling of the atmosphere to the heterogeneous land surface and how to represent this [3]. The results shown here are part of a model bench mark study organised within the GEWEX Atmospheric Boundary Layer Study (GABLS). Here GEWEX stands for the 'Global Energy and Water Exchanges Program (GEWEX)', which is a part of the World Climate Research Program. Over the years, I have played a role in this 


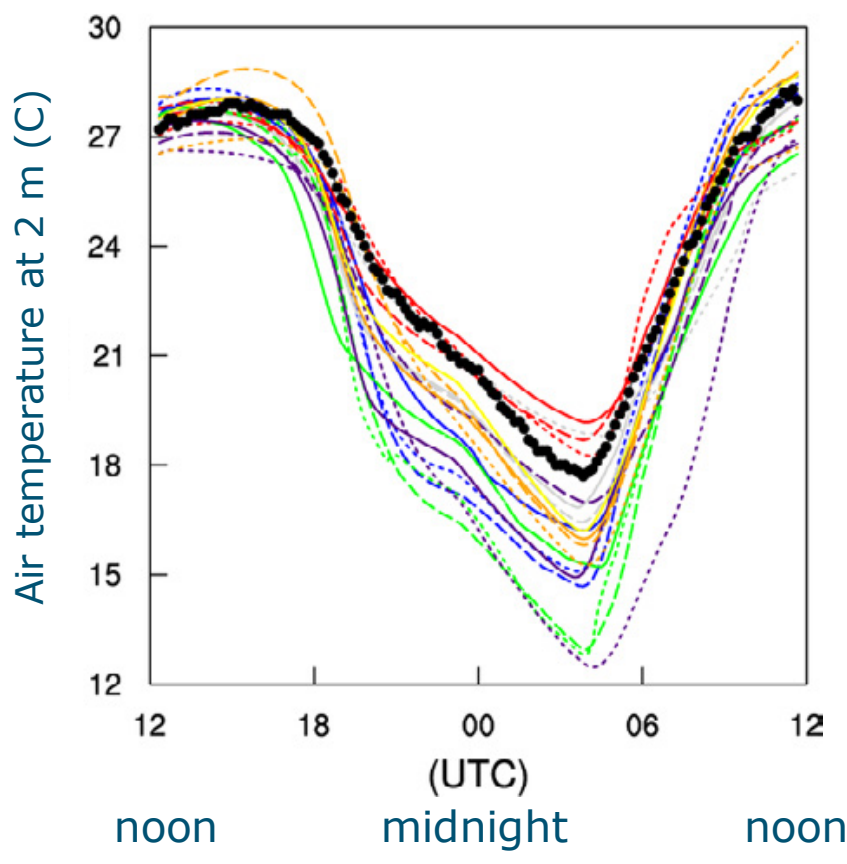

Figure 7-Model results for 2 meter air temperature over land in Cabauw as part of $\mathrm{GABLS}_{3}[3]$ program as initiator and co-chair of GABLS, by stimulating scientists at weather and climate centres to work with university staff and students to make progress in understanding and modelling of atmospheric boundary-layer processes [13].

To further advance the understanding and representation of atmospheric processes, the Dutch Atmospheric Science community can now benefit from a new

10 year program sponsored by the Netherlands Organisation for Scientific Research (NWO). Within this so-called Ruisdael program, five Dutch universities work together with six Dutch Research Institutes. With a budget of 18 Million Euro, significant enhancements will be made to the observational infrastructure and model simulation capabilities [21]. Undoubtedly this will lead to enhanced insights and model improvements, which are important for local and regional weather forecasts, air quality measures and climate scenarios. This will also create many interesting subjects to study for staff and students. Within the Ruisdael Observatory, the Wageningen research groups will take part with atmospheric observations at several sites, including the city of Amsterdam, the Loobos forest site, and our current weather station at the Veenkampen [26].

It may be noted that Wageningen University was early by doing weather and solar radiation observations. In fact, Wageningen solar observations have been done reliably since $1928[5,11]$. As such this is one of the longest series in Europe. From the observations it appears that the yearly average of solar radiation at the surface has significantly increased over the years (Figure 8). The increase relates to a cleaner 


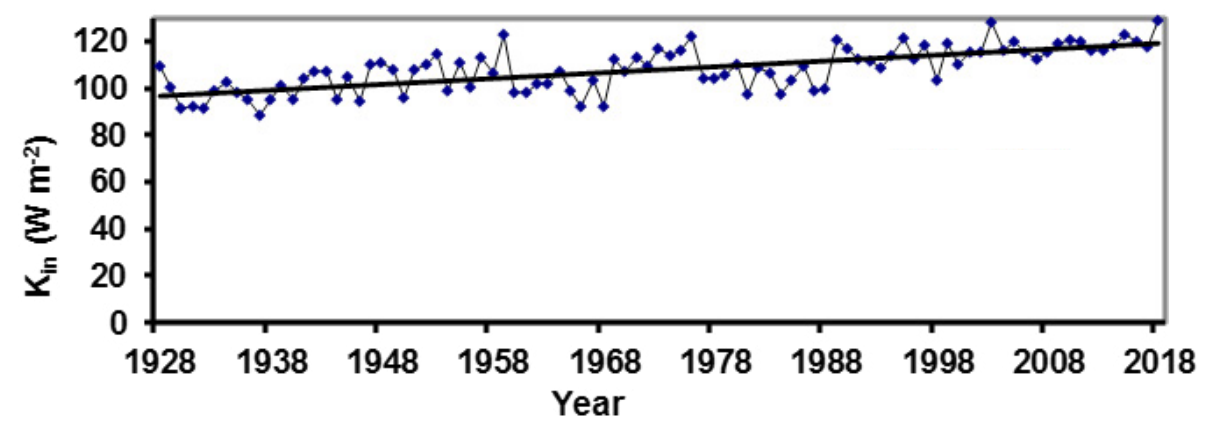

Figure 8 - The mean yearly solar radiation as observed in Wageningen since 1928 [5,11]

atmosphere and due to different cloud properties [2], and not because the sun has increased its energy. The increase of solar radiation at the surface is of course good news for solar energy applications. The weather and solar observations were started in the nineteen twenties by Prof. Dirk van Gulik and his group. Note that Van Gulik was the first professor of Meteorology at this university (and in a later stage he became Rector as well).

Originally the observations of radiation and weather were done near the university buildings at 'Duivendaal' but that ended in 1961. Subsequently, the measurements were continued at the 'Haarweg' site till 2011, and since 2010 at the 'Veenkampen' in the region between Wageningen and Rhenen [26]. The reason of moving the weather sites is the significant expansion of the city of Wageningen over the years. This brings me to the next topic of this presentation.

\section{Impacts of Land Use and Urbanization on the Atmosphere}

In many parts of the world, urbanisation has been very strong in the last century. This can have significant impact on rural weather observations, which deserves attention before using the observations for climate records [17]. For instance, by doing parallel measurements in 2011 on two nearby 'Haarweg' and 'Veenkampen' weather sites, an estimate can be given on the impact of the warmer city of Wageningen on the downwind temperature observations [11]. It appears that the yearly averaged temperature impact during 2011 is as large as $I^{\circ} \mathrm{C}$ during SouthEasterly winds. Averaged over all wind directions the difference is only $0.2{ }^{\circ} \mathrm{C}$, but still substantial. Obviously, the urban downwind effect clearly has to be separated from the enhanced greenhouse effect, and this is an active field of research also at other locations. 


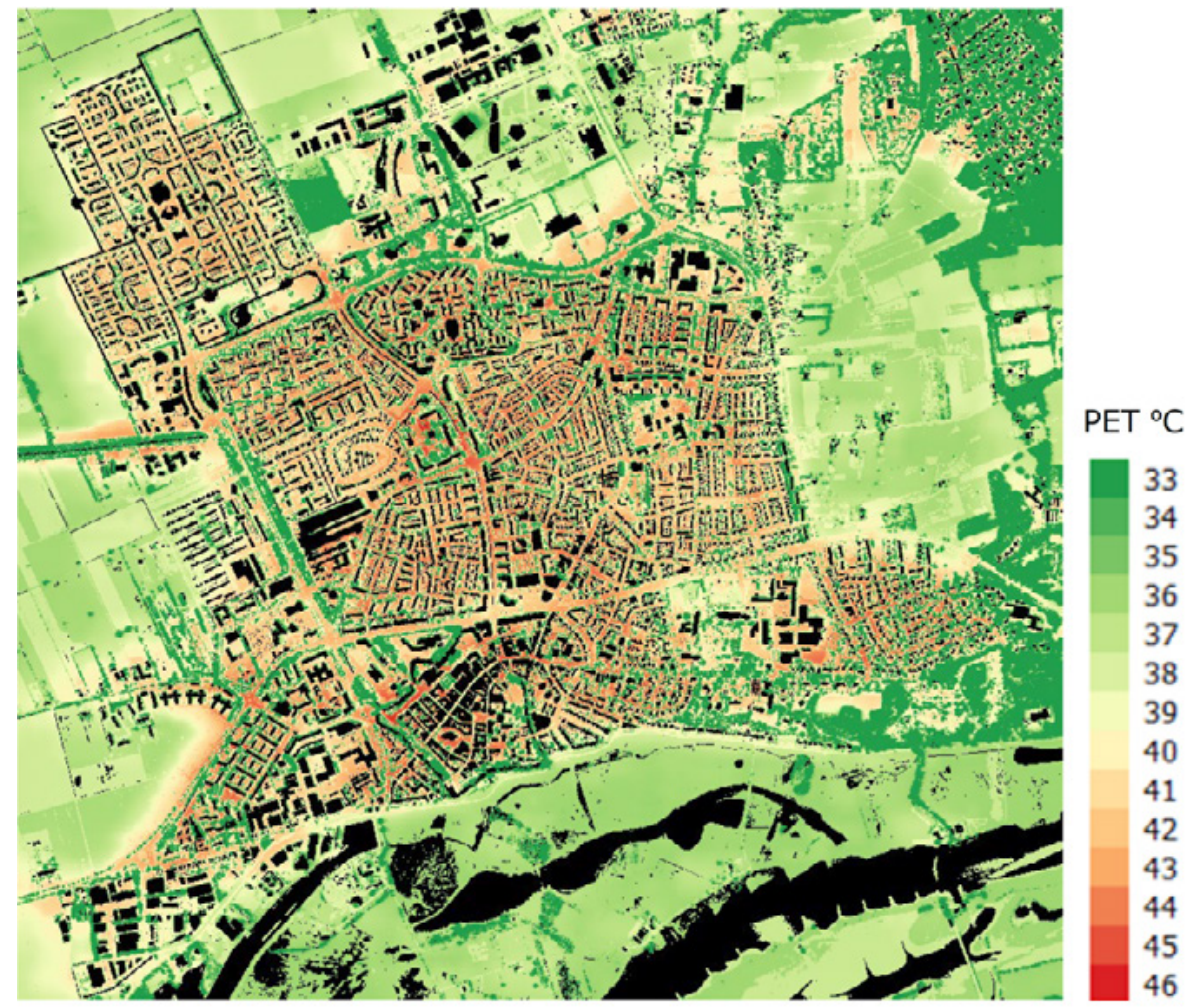

Figure 9-Heat map for Wageningen, July 1, 2015 (Courtesy Sytse Koopmans, Gert-Jan Steeneveld and Bert Heusinkveld)

The next question is, how much is the temperature within the city influenced by the city? For Wageningen, it appears that temperature observations made at the Market place can be $5^{\circ} \mathrm{C}$ larger than on the rural weather site of the Veenkampen for a nice summer day [11]. The difference between these two temperatures is known as the Urban Heat Island effect. The magnitude is related to the building and street materials of the urban area. In fact, observations in other Dutch cities have shown that the Urban Heat Island can be as large as 7 degrees or more $[9,24]$.

In the last decade the MAQ group has become quite involved in urban weather and climate studies in various Dutch cities, including Amsterdam, Arnhem, The Hague, Breda, Rotterdam, and of course Wageningen. By using a fully instrumented urban bike to observe the weather at street level, calculations can be made of human comfort given the weather and surroundings. This knowledge can be used to 
construct heat maps (Figure 9). Soon all Dutch cities and communities need to produce heat maps to inform the citizens, and the Wageningen recipe will be used for this as the basis.

As you will recall, in the summer of 2019 the weather in the Netherlands was unusually warm, sunny and dry. And cities were even warmer. Differences up to $4{ }^{\circ} \mathrm{C}$ were observed within the city of Amsterdam and also in comparison with observations outside the city at Schiphol airport [25]. The weather stations in Amsterdam are in operation since the summer of 2014, and the ambition is to extend the observations with other instruments as well. Also special measurement campaigns have been organised, including the launch of weather balloons. Overall this has received much media attention.

Typically weather forecasts are made for the rural landscape, but there is an obvious need for city forecasts as well. Very fine-scale weather forecasts have been made for Amsterdam with a horizontal resolution of only $100 \mathrm{~m}$ validated with the observations [22]. These forecasts reveal amazing detail, which may benefit citizens in particular on hot summer days. For instance, using this information, it is possible to guide pedestrians and cyclists to use the coolest route in the city. In combination with air quality forecasts, also the cleanest route can be advised. This is an active field of research, which certainly will receive more attention and improvements in the future.

It is very popular to look at the weather radar for the spots of precipitation, but the weather radar information can also be used to study the climatology of rain over longer periods after careful calibration of the observations with independent measurements. From these results a connection is apparent with land use and urban areas, in particular in winter time in the area between The Hague and Rotterdam. This area is known for its agricultural green houses. So besides of greenhouse gases in the atmosphere, here the regional climate is also influenced by land use effects. It also turns out that Dutch cities do enhance precipitation and this can amount by around $11 \%$ for the 5 largest cities [20].

For a sustainable future it is important that all energy resources are explored. However, solar and wind energy farms may also have a significant impact on local weather and climate. The impact can also be positive, in particular at night wind farms over land may prevent night frost if properly placed and integrated with the Agricultural land. In any case, for both solar and wind farms very fine scale forecasting of the weather is beneficial to make reliable energy forecasts. This nowadays creates a great opportunity for our students on the job market. 


\section{Ladies and Gentleman,}

I like to conclude this address by noting that many aspects of the Atmospheric dreams on understanding and modelling weather and climate have become true. The perspective for further advancing the understanding of atmospheric processes for weather, air quality and climate is excellent. However, major challenges still exist on topics such as land-atmosphere interactions, the impact of land-use and urban areas.

In this talk, I focussed on the atmospheric dreams and perspectives from the research point of view. Obviously these subjects are clearly relevant and challenging for academic education as well. The obvious dream is that our students really understand these subjects, make important contributions, and help with the outreach of the findings. And most of our students do this, and continue in interesting and challenging jobs in science and applications, or in advising jobs related to weather, air quality and climate!

\section{Acknowledgements}

Finally I would like to provide a 'thank you' and mention some persons. I have been active in Meteorology for 42 years, of which roughly 22 years at the Netherlands Meteorological Institute (KNMI), and 6 years at Utrecht University as a part-time professor of Meteorology. Over the years, I also made many visits to international institutes and universities, in particular to the National Center for Atmospheric Research (NCAR) in Boulder, CO.

I was able to work with many people to advance the science, and also to use the insights for interesting and relevant applications (in particular for wind, surface exchange processes, air quality dispersion and improving atmospheric models for weather and climate). As such I have been very lucky and I thank the many talented persons who advised and worked with me. I also like to thank the leadership at KNMI for giving me the opportunity to work on my PhD thesis [12], which I defended in this Auditorium on 16 June, 1987. As such I also like to mention the former professor of Meteorology at this university, Prof. Bert Wartena, and Dr Henk de Bruin for guiding me on my PhD thesis.

I also like to thank the speakers at the Symposium today, who gave nice overviews on the various aspects of my work with them over the years. So thank you to Anton Beljaars, Fred Bosveld, Bas van de Wiel, Mathias Rotach, Sukanta Basu, Gert-Jan Steeneveld and Michael Ek! And also thanks to Jordi Vila for his introduction and chairing the symposium today. I also like to thank the 
cooperation with three very talented persons, which unfortunately died at relatively young age, namely Peter Duynkerke, Frans Nieuwstadt and Byron Boville.

In May 1999 I started in Wageningen as a Professor of Meteorology and Air Quality. It was a new group, formed by the merging of the two subgroups of Meteorology and Air Quality. My first duty was to merge these groups and apply a severe budget cut, but I could also hire one new staff member. That person is Jordi Vila, who is now taking over the chair holder's position in Meteorology. In addition, Maarten Krol started as chair holder of Air Quality on November 1, 2005. With the great help of Jordi and Maarten, and the additional hiring of talented staff members, Post-Docs and PhD students, the Meteorology and Air Quality section has expanded and became quite successful. And the future perspectives are great for the group (Figure 10). I hope to stay connected after my official retirement by co-advising PhD students, and working on some of the unresolved scientific issues. The topics are too nice and too interesting to let go.

Last but certainly not the least, I like to thank my wife Monique, our sons Joost and Wouter, as well as their girlfriends Marrianne and Sofie for their love and support.

Thank you very much for your attention!

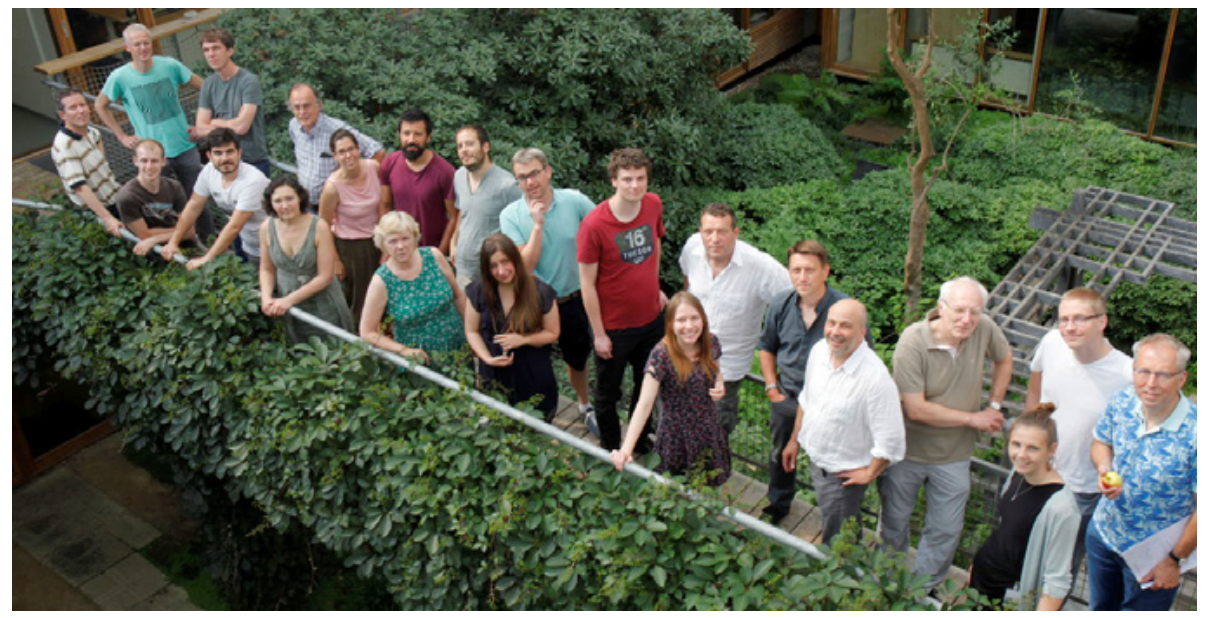

Figure 10 - Group photo of the staff at Meteorology and Air Quality Section in June 2018 (not complete) 


\section{References}

[1] Bauer P., A. Thorpe, and G. Brunet, 2015: The quiet revolution of numerical weather prediction, Nature, 525, 47-55, https://www.nature.com/articles/ nature 14956

[2] Boers, R., T. Brandsma, and A. P. Siebesma, 2017: Impact of aerosols and clouds on decadal trends in all-sky solar radiation over the Netherlands (1966-2015), Atmos. Chem. Phys., 17, 8081-8100, https://doi.org/10.5194/acp-17-8081-2017

[3] Bosveld, F.C., P. Baas, G.J. Steeneveld, A.A.M. Holtslag, W.M. Angevine, E. Bazile, E.I.F. de Bruijn, D. Deacu, J.M. Edwards, M. Ek, V.E. Larson, J.E. Pleim, M. Raschendorfer, G. Svensson, 2014: The Third GABLS Intercomparison Case for Evaluation Studies of Boundary-Layer Models. Part B: Results and Process Understanding. Boundary-Layer Meteor., 152, 157-187.

[4] Buisman. J, 2011, Extreme Weather!, Van Wijnen, 576p. (pages 303-305 refer to the Borculo extreme weather event, in Dutch).

[5] De Bruin, H. A., B. J. van den Hurk, and D. Welgraven, D., 1995: A series of global radiation at Wageningen for 1928-1992. Int. J. Climatol., 15: 1253-1272, https://doi:10.1002/joc.3370151106

[6] Ek, M.B. and A.A.M Holtslag, 2004: Influence of Soil Moisture on Boundary Layer Cloud Development. J. Hydrometeor., 5, 86-99, https://doi. org/10.1175/1525-7541(2004)005<0086:IOSMOB>2.0.CO;2

[7] Frisinger, H., 1972: Aristotle and his "Meteorologica". Bull. Amer. Meteor. Soc., $53,634-638$.

[8] Hawkins, E., T. Fæhn, and J. Fuglestvedt, 2019: The Climate Spiral Demonstrates the Power of Sharing Creative Ideas. Bull. Amer. Meteor. Soc., 100, 753-756, https://doi.org/10.1175/BAMS-D-18-0228.1 (see also http://www. climate-lab-book.ac.uk/spirals/)

[9] Heusinkveld, B.G., G.J. Steeneveld, L.W.A. van Hove, C.M.J. Jacobs, A.A.M. Holtslag, 2014: Spatial variability of the Rotterdam urban heat island as influenced by urban land use. J. Geophysical Res.-Atmospheres, 119, 677 - 692.

[10] Heusinkveld, B.G., G. Sterenborg, G.J. Steeneveld, J.J. Attema, R.J. Ronda, A.A.M. Holtslag, 2017: Smartphone App brings human thermal comfort forecast in your hands. Bull. Amer. Meteor. Soc., 98, 2533-2541, https://doi. org/10.1175/BAMS-D-16-0082.1

[11] Heusinkveld, B.G. (personal communication).

[12] Holtslag, A.A.M., 1987, Surface fluxes and boundary layer scaling - Models and applications, $\mathrm{PhD}$ thesis, Wageningen University, 175 pages (defended June 16, 1987).

[13] Holtslag, A.A.M, G. Svensson, P. Baas, S. Basu, B. Beare, A.C. Beljaars, F.C. Bosveld, J. Cuxart, J. Lindvall, G.J. Steeneveld, M. Tjernström, and B.J. Van De Wiel, 2013: Stable Atmospheric Boundary Layers and Diurnal Cycles - 
Challenges for Weather and Climate Models. Bull. Amer. Meteor. Soc., 94, 1691-1706, https://doi.org/10.1175/BAMS-D-11-00187.1

[14] IPCC, 2019: Climate Change and Land - An IPCC Special Report on climate change, desertification, land degradation, sustainable land management, food security, and greenhouse gas fluxes in terrestrial ecosystems. https://www.ipcc. $\mathrm{ch} / \mathrm{report} / \mathrm{srccl} /$

[15] Jakob, C., 2010: Accelerating Progress in Global Atmospheric Model Development through Improved Parameterizations. Bull. Amer. Meteor. Soc., 91, 869-876, https://doi.org/10.1175/2009BAMS2898.1

[16] Kesteren, A.J.H. van, O.K. Hartogensis, D. van Dinther, A.F. Moene, H.A.R. de Bruin, and A.A.M. Holtslag, 2013: Measuring $\mathrm{H}_{2} \mathrm{O}$ and $\mathrm{CO}_{2}$ fluxes at field scales with scintillometry: Part II-Validation and application of 1-min flux estimates. Agricultural and Forest Meteorology, 178-179, 88 - 105.

[17] Koopmans, S., N.E. Theeuwes, G.J. Steeneveld, A.A.M. Holtslag, 2015: Modelling the influence of urbanization on the temperature record of weather station De Bilt (Netherlands) in the 2oth century, Int. J. Climatol., 35, 1732-1748.

[18] KNMI website for actual results of Ensemble Prediction System (EPS): https:// www.knmi.nl/nederland-nu/weer/waarschuwingen-en-verwachtingen/ weer-en-klimaatpluim

[19] Lorenz, E.N., 1963: Deterministic Nonperiodic Flow. J. Atmos. Sci., 20, 130-141.

[20] Manola, I., G.J. Steeneveld, R. Uijlenhoet, A.A.M. Holtslag, 2019: Urban precipitation across scales from radar observations in the Netherlands and the associated synoptic weather types, Int. J. Climatol., https://doi.org/10.1002/joc.6241

[21] Ruisdael Observatory, see http://ruisdael-observatory.nl/

[22] Ronda, R.J., G.J. Steeneveld, B.G. Heusinkveld, J.J. Attema, and A.A.M Holtslag, 2017: Urban fine-scale forecasting reveals weather conditions with unprecedented detail, Bulletin of the American Meteorological Soc., 98 2675-2688, https://doi.org/10.1175/BAMS-D-16-0297.1

[23] M. Sikma, H.G. Ouwersloot, X. Pedruzo-Bagazgoitia, C.C. van Heerwaarden, J. Vilà-Guerau de Arellano, 2018: Interactions between vegetation, atmospheric turbulence and clouds under a wide range of background wind conditions. Agricultural and Forest Meteorology, 255, 31-43, https://doi.org/10.1016/j. agrformet.2017.07.001

[24] Steeneveld, G.J., S. Koopmans, B.G. Heusinkveld, L.W.A. van Hove, and A.A.M. Holtslag, 2011: Quantifying urban heat island effects and human comfort for cities of variable size and urban morphology in The Netherlands, J. Geophys. Res., 116, D20129, doi:10.1029/2011JDo15988.

[25] Steeneveld, G.J., B.G. Heusinkveld, O.K. Hartogensis, 2019: Stadswarmte tijdens een hittegolf vastgelegd met radiosondes in Amsterdam, Meteorologica, 28 (3) 18-20 (in Dutch). 
[26] Veenkampen Weather Information, Wageningen, https://www.wur.nl/en/show/ Weather-Station-De-Veenkampen.htm

[27] Vos, L. de, A. Droste, M. Zander, A. Overeem, H. Leijnse, B. Heusinkveld, G. Steeneveld, and R. Uijlenhoet, 2019: Hydrometeorological monitoring using opportunistic sensing networks in the Amsterdam metropolitan area. Bull. Amer. Meteor. Soc., https://doi.org/10.1175/BAMS-D-19-oog1.1

[28] Webster, E.W., 1931: Translation of "Meteorologica" by Aristotle (Internet Archive, https://archive.org/details/workstranslatediozarisuoft/page/n15

[29] Wikipedia, 2019: Weather lore, see https://en.wikipedia.org/wiki/Weather lore

[30] Zillman J.W., 1999, Weather and climate information products with corresponding spatial and temporal scales. WMO Bulletin 48, (2), April 1999. 



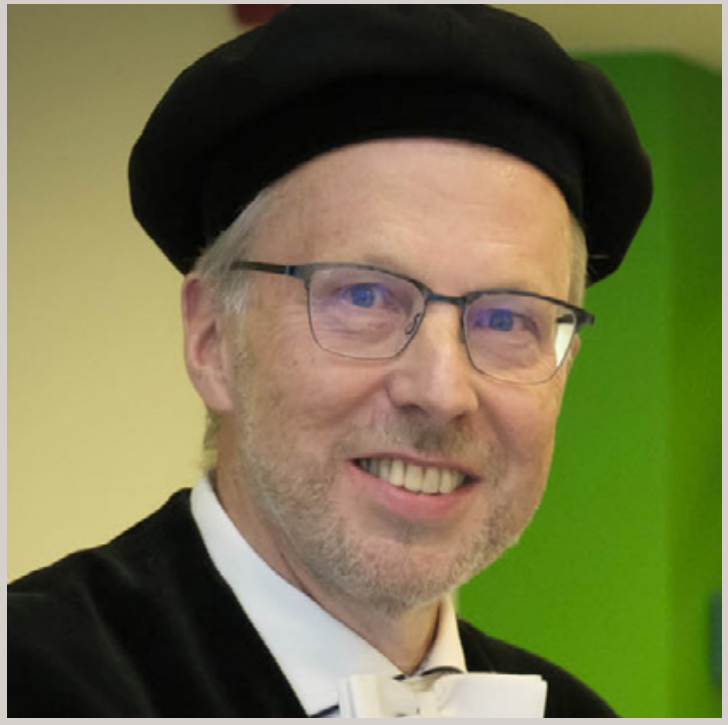

Prof.dr Bert Holtslag

This farewell address on "Atmospheric Dreams and Perspectives" deals with the silent revolution in Meteorology within the last decades, the enhanced understanding and remaining challenges to represent atmospheric processes in models for weather and climate, and the impacts of land use and urbanisation on the atmosphere. 